\title{
Penerapan Algoritma Convolutional Neural Network dalam Klasifikasi Telur Ayam Fertil dan Infertil Berdasarkan Hasil Candling
}

\author{
Muhammad Rizky Firdaus \\ Fakultas Industri Kreatif dan Telematika, Universitas Trilogi, Jl. Duren Tiga Timur No.30 Kota \\ Jakarta Selatan, Indonesia, 12760 \\ e-mail: rizkyfirdaus0309@gmail.com
}

Submitted Date: December $25^{\text {th }}, 2020$

Revised Date: December $31^{\text {th }}, 2020$
Reviewed Date: December $31^{\text {th }}, 2020$

Accepted Date: January $05^{\text {th }}, 2021$

\begin{abstract}
Fertile chicken eggs are eggs that can hatch because these eggs have a development in the form of dots of blood and blood vessels or can be called an embryo, while infertile chicken eggs are a type of egg that cannot be hatched because there is no embryo development in the hatching process. Inspection of infertile chicken eggs must be carried out especially for breeders who will carry out the selection and transfer of fertile chicken eggs and infertile chicken eggs. However, currently, the selection of fertile and infertile chicken eggs is still using a less effective way, namely only by looking at the egg shell or called candling, this process is certainly less accurate to classify which eggs are fertile and infertile eggs because not all breeders are able to see the results of the eggs properly. candling so that the possibility of prediction errors. Therefore, in this study, a classification of fertile chicken eggs and infertile chicken eggs will be carried out based on candling results using the Convolutional Neural Network method. From the results of the classification carried out, the percentage of accuracy obtained for the classification of fertile and infertile chicken eggs is $98 \%$ and an error of $5 \%$.
\end{abstract}

Keywords: Fertile Eggs; Infertile Eggs; Convolutional Neural Network; Deep Learning

\begin{abstract}
Abstrak
Telur fertil merupakan telur yang dapat menetas karena pada telur ini terdapat suatu perkembangan yang berbentuk nokta darah atau bisa disebut sebagai embrio sedangkan Telur ayam infertil merupakan jenis telur yang tidak dapat ditetaskan karena tidak adanya perkembangan embrio pada proses penetasan. Pemeriksaan telur ayam infertil harus dilakukan terutama bagi para peternak yang akan melakukan penseleksian serta pemindahan mana telur ayam fertil dan telur ayam infertil. Namun, saat ini penseleksian telur ayam fertil dan infertil ini masih menggunakan cara yang kurang efektif yaitu hanya dengan meneropong cangkang telur atau disebut dengan candling proses ini tentunya kurang akurat untuk mengklasifikasikan mana telur fertil dan telur infertil karena tidak semua peternak mampu melihat dengan baik hasil dari candling tersebut sehingga kemungkinan terjadinya kesalahan prediksi. Dari permasalahan tersebut, maka dalam penelitian ini akan dilakukan klasifikasi telur ayam fertil dan telur ayam infertil berdasarkan hasil candling dengan metode Convolutional Neural Network. Dari hasil klasifikasi yang dilakukan, persentase akurasi yang didapatkan untuk klasifikasi telur ayam fertil dan infertil adalah $98 \%$ dan error sebesar $5 \%$.
\end{abstract}

Kata Kunci: Telur Fertil; Telur Infertil; Convolutional Neural Network; Deep Learning

\section{Pendahuluan}

Salah satu sumber makanan yang sering dikonsumsi di Indonesia yaitu telur. Karena nilai gizi yang dikandung oleh telur ini sangat bermanfaat dan harga yang relatif lebih murah membuat banyak masyarakat Indonesia menyukai sumber makanan ini. Telur ayam adalah salah satu telur yang sering dikonsumsi oleh beberapa masyarakat Indonesia. Bahkan, hampir seluruh kalangan mengkonsumsi telur jenis ini karena 
relatif lebih murah dan mudah untuk diperoleh selain itu juga telur ini memiliki nilai gizi yang baik (Maimunah \& Rokhman, 2018). Jenis penghasilan telur ini dibagi menjadi dua kelompok yaitu telur yang dapat ditetaskan (fertile) dan telur yang tidak dapat ditetaskan (infertile). Telur fertil merupakan telur yang dapat menetas karena pada telur ini terdapat suatu perkembangan yang berbentuk nokta darah atau bisa disebut sebagai embrio (Nurdiyah \& Muwakhid, 2016). Telur fertil ini dapat menetas karena di dalam telur tersebut memiliki sperma dari ayam jantan sehingga telur-telur fertil ini bisa untuk dikonsumsi maupun ditetaskan. Jika telur fertil ini dierami dengan suhu yang tepat maka kemungkinan besar telur ini akan menetas. Namun, tidak semua jenis telur fertil ini dapat menetas karena untuk proses penetasan ini telur harus melalui proses inkubasi selama beberapa jam lalu disimpan pada suhu yang tepat agar embrio berkembang dan kemudian menetas. Telur fertil biasanya akan menetas selama kurang lebih 21 hari. Agar terhindar dari berbagai bakteri dan penyakit pada telur fertil ini, penetasan telur membutuhkan benih berkualitas agar ayam yang menetas dapat sehat dan tahan terhadap penyakit (Diantoro \& Santoso, 2017). Sedangkan telur infertil merupakan jenis telur yang tidak dapat ditetaskan karena tidak adanya perkembangan embrio pada proses penetasan. Pada Dasarnya telur ini juga dibuahi oleh jantan namun ketika proses penetasan, telur jenis ini ternyata tidak dapat menetas (ISNAWATI, 2018). Meskipun telur fertil dan telur infertil dapat dikonsumsi, hasil telur dari kedua proses ini terdapat beberapa perbedaan yaitu; menurut penelitian (Nawawi, Rahmad, \& Syahputra, 2015) dijelaskan bahwa telur infertil bisa menjadi tempat berkembang biak jamur hal tersebut disebabkan karena terdapat perbedaan suhu pada telur dan suhu yang diwakili oleh termometer inkubator, telur infertil biasanya akan lebih cepat membusuk daripada telur fertil, karena kontaminasi jamur atau bakteri yang ada pada telur infertil dapat menghasilkan tekanan yang memungkinkan telur tersebut pecah di inkubator. Pemeriksaan telur ayam infertil harus dilakukan terutama bagi para peternak yang akan melakukan penseleksian serta pemindahan mana telur ayam fertil dan telur ayam infertil. Namun, saat ini penseleksian telur ayam fertil dan infertil ini masih menggunakan cara yang kurang efektif yaitu hanya dengan meneropong cangkang telur atau disebut dengan candling proses ini tentunya kurang akurat untuk mengklasifikasikan mana telur ayam fertil dan telur ayam infertil karena tidak semua peternak mampu melihat dengan baik hasil dari candling tersebut sehingga kemungkinan terjadinya kesalahan prediksi. Dengan menerapkan Algoritma Convolutiunal Neural Network penseleksian tersebut dapat dilakukan secara lebih efektif sehingga membuat para peternak telur ayam lebih mudah untuk melakukan penseleksian. Penseleksian dilakukan dengan cara meneropong cangkang telur kemudian mengolah hasil peneropongan tersebut menggunakan Algoritma Convolutional Neural Network dengan beberapa dataset yang sudah dikumpulkan melalui studi lapangan metode ini mampu untuk mengklasifikan telur ayam fertil dan telur ayam infertil.

\section{Tinjauan Pustaka}

Dalam penelitian dibutuhkan dukungan penelitian dari penelitian sebelumnya. Penulis telah mengumpulkan tiga literatur yang berhubungan dengan penelitian ini. Penelitian (Arini, Ubaidillah, Wibisono, \& Ulum, 2020). Dalam penelitian ini dijelaskan bahwa untuk meningkatkan persentase dalam proses penetasan telur dibutuhkan suatu penanganan yang dapat memisahkan mana telur fertil dan mana telur infertil. Penanganan yang dilakukan untuk pemisahan telur tersebut dapat dilakukan dengan proses candling atau peneropongan telur. Hasil dari penelitian ini adalah sebuah sistem yang dapat mengidentifikasi telur yang fertil dan telur infertil. Metode yang digunakan dalam penelitian ini adalah Image Processing. Terdapat perbedaan dengan penelitian yang dilakukan Nur Farida Arini, Achmad Ubaidillah, Kunto Aji Wibisono dan Miftachul Ulum dengan penelitian yang dilakukan saat ini yaitu metode yang digunakan peneliti saat ini adalah Algoritma Convolutional Neural Network meskipun metode ini sama dengan Image Processing namun arsitektur yang diterapkan berbeda dan juga pada penelitian saat ini belum ada sistem yang dapat digunakan untuk melakukan klasifikasi telur fertil dan telur infertil. Penelitian (Prasmatio, Rahmat, \& Yuniar, 2020). Dalam penelitian ini dijelaskan bahwa jumlah pakar ikan yang ada di Indonesia tidak mencukupi untuk melakukan identifikasi ikan yang ada Indonesia. Oleh sebab itu dibutuhkan suatu sistem yang dapat membantu para pakar tersebut dalam mengidentifikasi jenis ikan. Sistem identifikasi ini akan menerapkan Algoritma Convolutional Neural Network dalam proses identifikasinya. Hasil dari penelitian ini adalah suatu sistem yang dapat mempermudah para pakar ikan dalam mengidentifikasi jenis-jenis ikan yang ada di 
Indonesia. Perbedaan penelitian yang dilakukan R. Mehindra Prasmatio, Basuki Rahmat, Intan Yuniar dengan penelitian saat ini adalah penerapan dari metode yang dilakukan, digunakan untuk mengidentifikasi jenis-jenis ikan yang ada di Indonsia dan pada penelitian saat ini metode diterapkan dalam mengklasifikasi jenis telur fertil dan telur infertil. Penelitian (Nurdiyah, Santosa, \& Pramunendar, 2015). Dalam penelitian dijelaskan bahwa pengujian fertilitas telur masih banyak yang menggunakan cara konvensional yaitu dengan memanfaatkan proses candling atau peneropongan, sehingga membuat waktu yang lama untuk pemrosesan tersebut. Dari permasalahan tersebut penelitian ini memberikan solusi dengan menggunakan teknologi Computer Vision yang dapat mengenali objek berdasarkan ciri-ciri dari objek tersebut sehingga dapat diklasifikasikan. Hasil dari penelitian ini adalah sebuah teknologi yang dapat mempermudah untuk melakukan pengujian fertilitas telur dengan menerapkan metode Support Vector Machine. Perbedaan penelitian yang dilakukan dengan penelitian saat ini adalah metode yang diterapkan dalam klasifikasi telur fertil dan infertil. Pada penelitian Dewi Nurdiyah, Stefanus Santosa, Ricardus Anggi Pramunendar menerapkan Support Vector Machine sedangan penelitian saat ini menggunakan Convolutional Neural Network.

\section{Metodologi Penelitian}

Metode penelitian yang dilakukan yaitu dengan mengumpulkan beberapa sumber literatur dari penelitian terkait melalui jurnal. Selanjutnya adalah pengambilan sampel data dari telur fertil dan infertil. Lalu mengaplikasikan metode Algoritma Convolutional Neural Network untuk mengklasifikasikan telur fertil dan telur infertil.

A. Pengumpulan Data Telur

Pengumpulan data telur dilakukan dengan pengambilan gambar hasil penoropongan telur di lapangan. Data-data yang telah didapatkan tersebut nantinya akan digunakan untuk proses klasifikasi menggunakan Algoritma Convolutional Neural Network.

B. Algoritma Convolutional Neural Network Convolutional Neural Network (CNN) adalah algoritma yang termasuk dalam jenis Deep Neural Network, karena algoritma ini memiliki kedalaman jaringan yang tinggi. Algoritma $\mathrm{CNN}$ juga merupakan pengembangan dari Multilayer
Perceptron yang dirancang untuk pengolahan data berbentuk dua dimensi.
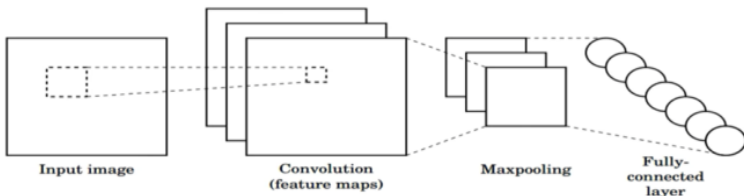

Gambar 1. Proses Convolutional Neural Nework

Algoritma Covolutional Neural Network lebih banyak diimplementasikan pada pengolahan data citra (Putra, 2016). Dalam Algoritma Convolutional Neural Network setiap neuron dipresentasikan dalam bentuk dua dimensi, cara kerja tersebut hampir mirip pada Multilayer Perceptron perbedaannya yaitu pada Multilayer Perceptron neuron dipresentasikan dalam bentuk ukuran satu dimensi. Algoritma Convolutional Neural Network mempunyai beberapa layer yang mana layer tersebut nantinya digunakan untuk melakukan filtering pada setiap proses komputasinya, proses tersebut dinamakan training. Algoritma CNN ini terdiri dari tiga jenis layer yaitu; Convolutional Layer, Pooling Layer dan Fully Connected Layer, ketika layer ini telah ditumpuk menjadi satu arsitektur, Algoritma CNN telah terbentuk (O'Shea \& Nash, 2015). Proses dari tiga arsitektur tersebut dapat dilihat pada gambar 1.

\section{1) Convolutional Layer}

Convolutional layer melakukan operasi konvolusi, yaitu mengubah input menjadi feature maps dengan melakukan operasi dot antara matriks input dengan filter (Wulandari, Yasin, \& Widiharih, 2020). Filter ini memiliki ukuran height (panjang), width (lebar), heavy (tebal) tertentu. Berikut adalah gambaran dari proses Convolutional Layer. 


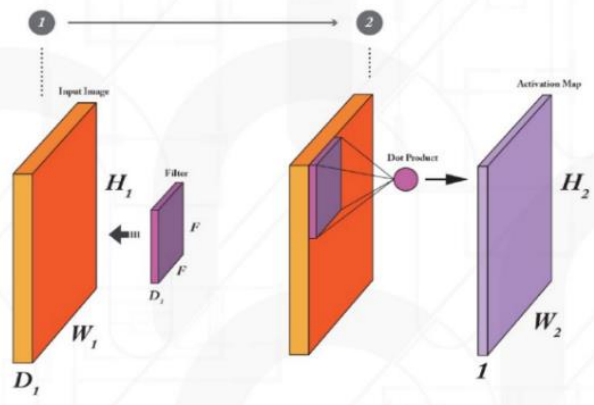

Gambar 2. Convolutional Layer

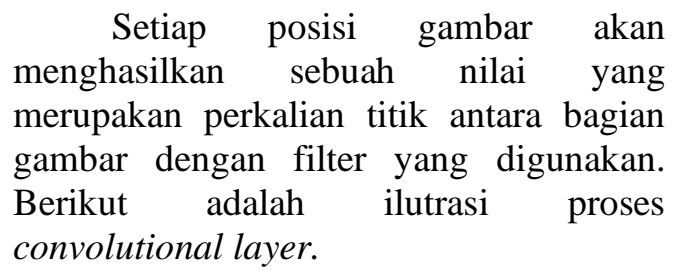

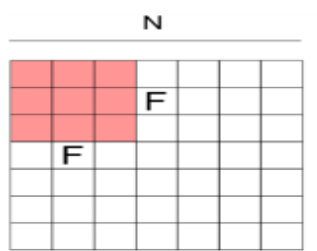

Gambar 3. Proses Convolutional Layer

Ukuran spasial dari proses output gambar di atas, dihitung menggunakan rumus:

$$
\frac{N-F+2 P}{S}+1
$$

Keterangan:

$\mathrm{N}$ : Ukuran spasial (tinggi $\mathrm{H} 1$ = lebar W1) dari input yang ada pada gambar.

F: Merupakan ukuran spasial filter

P: Suatu parameter di mana parameter ini menentukan jumlah pixel, lalu akan ditambahkan pada setiap sisi dari input, disebut juga sebagai Zero Padding

S: Besaran pergeseran filter pada setiap proses komputasi disebut juga dengan Stride.

Jika dilihat dari ilustrasi gambar di atas maka perhitungan komputasinya adalah sebagai berikut.

- $\mathrm{N}=7$

- $\mathrm{F} \quad=3$

- $\mathrm{P}$ (Padding) $=0$

- $\mathrm{S}$ (Stride) = 2 (Didapatkan berdasarkan pergeseran filter)
Stride $1 \rightarrow \frac{7-3+0}{1}+1=5$

Stride $2->\frac{7-3+0}{1}+2=3$

Proses komputasi ini akan diulang beberapa kali di setiap filter yang berbeda sampai menghasilkan beberapa kumpulan dari activation maps yaitu sebuah gambar baru.

2) Pooling Layer (Max Pooling)

Merupakan proses setelah Convulutional Layer. Pooling layer akan membagi beberapa nilai output dari proses convolution layer menjadi matriks yang lebih kecil, dengan mengambil nilai maksimal dari nilai matriks sebelumnya. Tujuannya adalah untuk mengurangi dimensi fitur matriks (Felix, Wijaya, Sutra, Kosasih, \& Sirait, 2020). Proses Pooling Layer dapat dilihat pada Gambar 4.
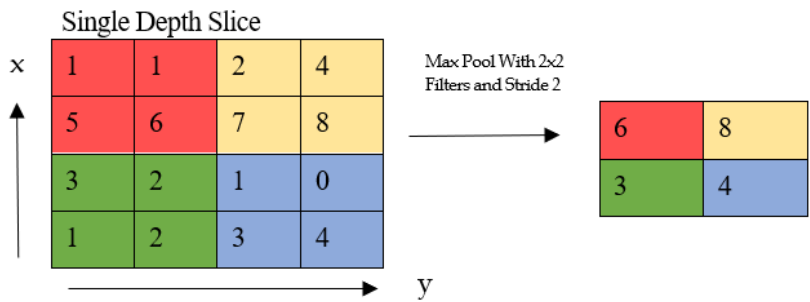

Gambar 4. Proses Pooling Layer

3) Fully Connected Layer

Hasil feature map dari kedua layer sebelumnya masih berbentuk multidimensional array oleh sebab itu diperlukan proses reshape feature map agar menjadi sebuah vector. Merupakan layer yang digunakan untuk melakukan transformasi pada data dimensi dengan tujuan data tersebut dapat diklasifikasikan secara linear. Neuron-neuron yang ada pada convolutional layer harus ditransformasikan kembali menjadi data array satu dimensi setelah itu dimasukkan ke dalam arsitektur ini. Proses ini bertujuan agar data yang ada tidak kehilangan informasi spasial dan tidak reversible. Arsitektur ini harus 
diimplementasikan pada akhir jaringan. (Ilahiyah \& Nilogiri, 2018).

\section{Hasil dan Pembahasan}

\section{A. Data Telur}

Data telur yang telah dikumpulkan dibagi menjadi dua kelas yaitu telur fertil dan telur infertil. Data kelas pertama yaitu telur fertil, data ini terkumpul menjadi 111 data dan data kelas kedua yaitu telur infertil terkumpul menjadi 138 data. Setelah itu kedua kelas ini dipecah kembali menjadi data training atau data latih dan data validasi. Data training telur fertil dibagi menjadi 88 data dan data training telur infertil dibagi menjadi 110 data. Lalu data validasi untuk telur fertil dibagi menjadi 23 data dan data validasi telur infertil dibagi menjadi 28 data. Data-data berikut dapat dilihat pada tabel 1 .

Tabel 1. Pembagian Data Telur Fertil dan Infertil

\begin{tabular}{|c|c|c|}
\hline Jenis Data & Telur Fertil & Telur Infertil \\
\hline Data Asli & 111 Data & 138 Data \\
\hline Data Training & 88 Data & 110 Data \\
\hline Data Validasi & 23 Data & 28 Data \\
\hline
\end{tabular}

B. Penerapan Convolutional Neural Network Proses penulisan code menggunakan Platform bernama Google Colab di mana platform ini dikhususkan untuk keperluan pengembangan dari Machine Learning. Sebelum memasuki proses penerapan Convolutional Neural Network pada klasifikasi telur fertil dan infertil ada beberapa library yang digunakan untuk proses tersebut yaitu library Tensorflow dan Keras. Tensorflow atau biasa disingkat dengan TF merupakan suatu library opensource yang digunakan untuk pengembanan Machine Learning. TensorFlow akan membagi sebuah komputasi graf yang telah ditentukan sebelumnya lalu menjalankannya secara paralel. Dengan Tensorflow ini, proses pelatihan model dari jaringan saraf akan menjadi lebih efisien. Lalu library Keras, library ini merupalan library yang dibangun di atas backend TensorFlow yang berfungsi untuk membuat sebuah image classifier. Dengan library Keras proses membangun jaringan saraf tiruan untuk klasifikasi gambar akan menjadi lebih mudah. Penggunaan dari library tersebut dilakukan dengan cara mengimpor pada header. Pada Gambar 5 dapat dilihat baris kode untuk mengimpor library tersebut.

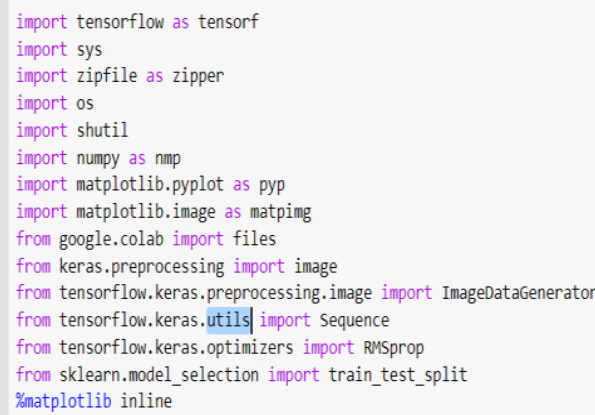

Gambar 5. Mengimpor library Tensorflow dan Keras

Selanjutnya adalah membuat direktori untuk menampung data latih dan data validasi dari dataset telur fertil dan infertil. Setelah membuat dua direktori data latih dan data validasi selanjutnya dataset telur fertil dan infertil dipecah kembali ke dalam direktori latih dan direktori validasi. Proses pembagian data dapat dilihat pada Gambar 6 .

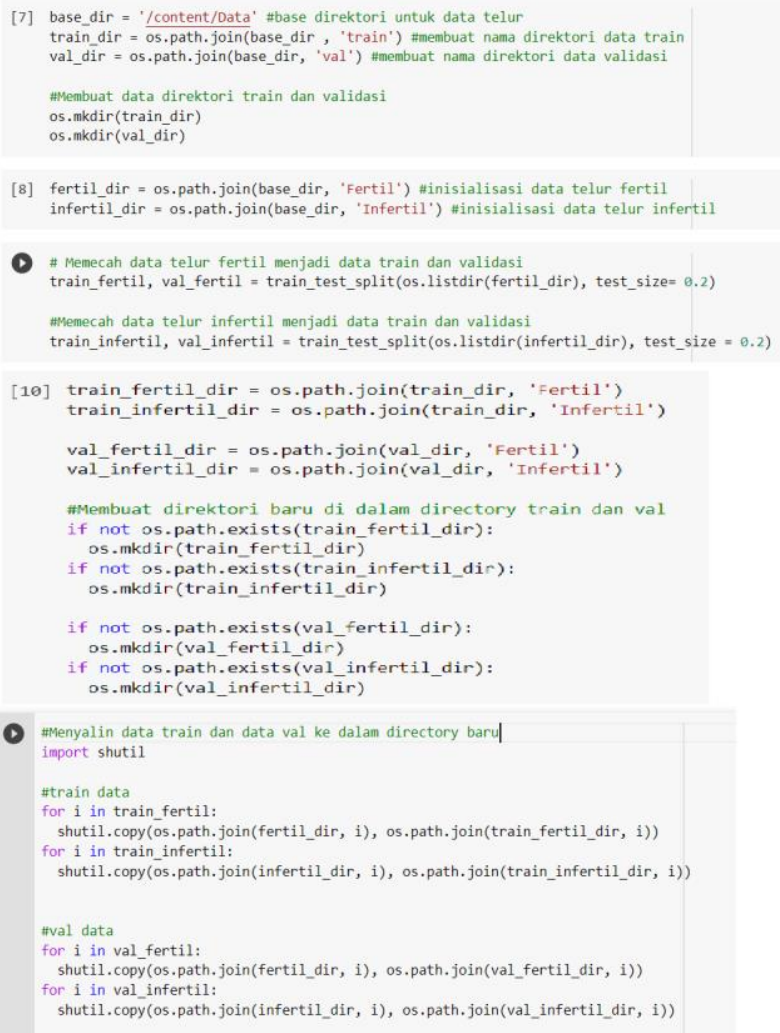

Gambar 6. Proses Pembagian Data Latih dan Validasi 
Setelah proses pembagian data telah selesai, maka selanjutnya adalah mempersiapkan data latih dan data testing yang nantinya akan diberikan ke model. Proses ini menggunakana Image Data Generator yang telah tersedia di dalam library Tensorflow. Fungsi dari Image Data Generator adalah melakukan preprocessing data, pelabelan sampel dan augmentasi gambar. Proses augmentasi gambar bertujuan untuk membuat data-data baru dari data yang telah ada. Pada gambar 7 dapat dilihat proses dari augmentasi gambar pada setiap dataset.

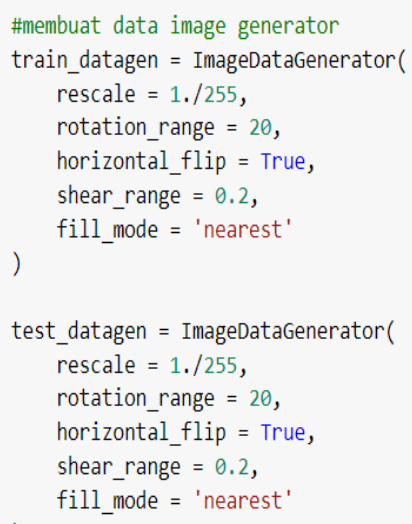

Gambar 7. Proses Augmentasi Gambar

Selanjutnya adalah melakukan training pada model dengan mempersiapkan data latih yang telah dipecah sebelumnya. Proses training dapat dilihat pada gambar 8 .

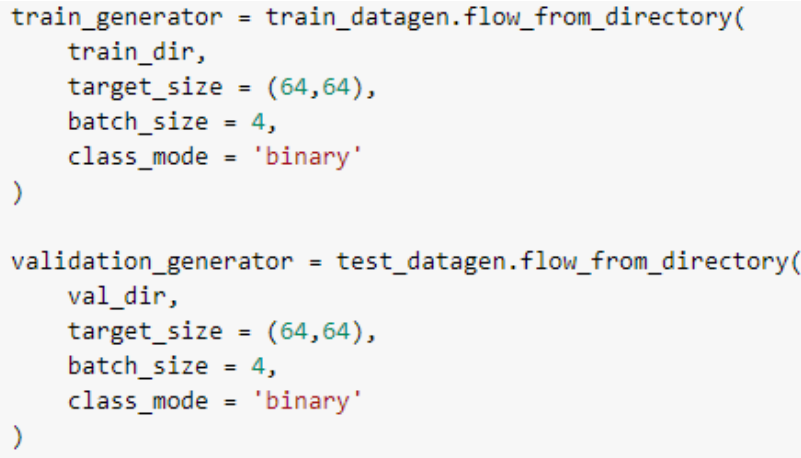

Found 238 images belonging to 2 classes.

Found 91 images belonging to 2 classes.

\section{Gambar 8. Proses training}

Dapat dilihat bahwa output menampilkan banyak data dari data latih dan data validasi. Di mana data latih menampilkan 198 gambar yang terbagi menjadi 2 kelas dan data validasi menampilkan 51 gambar yang terbagi menjadi 2 kelas. Setelah proses ini selanjutnya adalah membangun arsitektur dari Convolutional Neural Network. Baris kode untuk membangun arsitektur Convolutional Neural Network dapat dilihat pada gambar 9 .

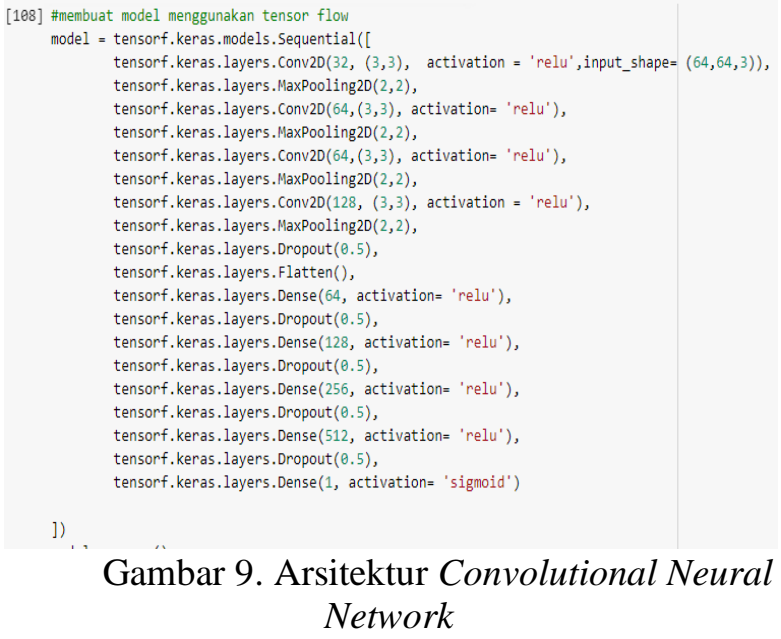

Gambar 9. Arsitektur Convolutional Neural Network

1. Convolutional Layer

Dari baris kode pada gambar 9 proses Convolutional Layer terdapat pada fungsi Conv2D yang berguna untuk melakukan konvolusi pada ukuran gambar, di mana parameter pertama mendefinisikan jumlah filter, parameter kedua adalah dimensi filter, parameter ketiga adalah fungsi aktivasi di mana fungsi aktivasinya menggunakan $R e L u$, lalu pada proses Convolutional Layer pertama terdapat input shape yang artinya bentuk input dari gambar bertipe RGB dengan ukuran 64x64 pixel dengan jumlah channel adalah 3. resolusi gambar dari data training. Gambar-gambar yang terdapat pada dataset memiliki resolusi gambar 150x150 pixel dan jumlah channel adalah 3 lalu jumlah filter adalah $3 \times 3$.

2. Max Pooling

Max Pooling terdapat setelah proses konvolusi layer. Proses Max Poolingi terdapat pada fungsi MaxPooling yang memiliki 1 parameter yaitu jumlah pooling dalam bentuk matriks di mana dalam kasus ini jumlah polling yang diinisialisasi adalah $2 \times 2$ yang berguna sebagai pixel loss dan precise region. Tujuan dari proses ini adalah untuk mereduksi resolusi gambar sehingga proses pelatihan dari model akan lebih cepat. Proses konvolusi layer dan max pooling dilakukan beberapa kali, dalam kasus ini 2 proses tersebut dilakukan sebanyak 
4 kali dengan nilai layer yang berbeda. Input shape hanya dilakukan pada proses konvolusi di layer pertama yaitu 32 .

\section{Fully Connected Layer}

Setelah dua proses tadi, hasil dari matriks input masih berbentuk 2 dimensi sehingga perlu dilakukan perubahan kembali menjadi matriks 1 dimensi. Proses perubahan ini menggunakan fungsi Flatten, di mana fungsi ini berguna untuk meratakan hasil dari feature map input yang telah diproses pada 2 layer sebelumnya. Lalu juga ada fungsi Dense yang berguna untuk menambahkan lagi layer pada proses fully Connected dengan parameter units dan aktifasi yang digunakan. Units menandakan jumlah Node yang ada pada hidden layer dan nilai yang diambil adalah nilai jumlah antara Node Input dan Node Ouput. Selanjutnya adalah menginisialisasi output layer dengan menggunakan fungsi Dense dengan parameter pertama adalah jumlah node yang menandakan label kelas dari data, karena pada kasus ini hanya terdapat 2 kelas maka jumlah unit diberikan nilai 1 yang artinya 0 adalah kelas pertama dan 1 adalah kelas kedua dan aktifasi yang digunakan adalah Sigmoid untuk klasifikasi dua kelas. Setelah arsitektur CNN telah dibangun, selanjutnya adalah melakukan kompilasi dari model tersebut. Pada gambar 10 dapat dilihat baris kode yang melakukan proses kompilasi.

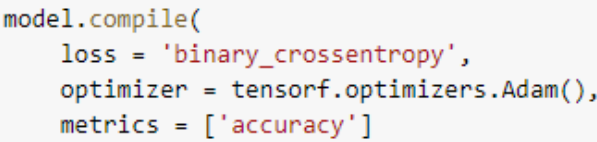

Gambar 10. Proses Kompilasi Model

Pada proses kompilasi terdapat 3 parameter yaitu: parameter loss yang berfungsi untuk menentukan loss function dengan menggunakan library dari keras yaitu binary_crossentropy, parameter kedua adalah parameter optimasi yang berguna untuk penentuan algoritma stochastic gradient descent dengan menggunakan library Adam dari TensorFlow, lalu parameter ketiga adalah parameter metrics yang berfungsi untuk penentuan performa dari metrics. Selanjutnya adalah melakukan proses training pada model menggunakan metode fit. Baris kode untuk proses training dapat dilihat pada Gambar 11.

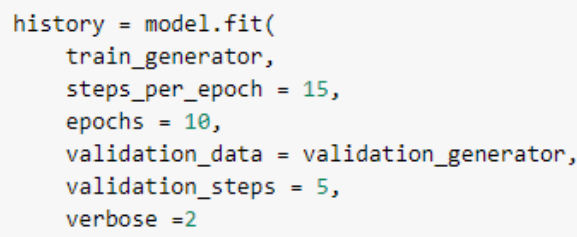

\section{Gambar 11. Proses Training}

Metode fit ini memiliki 6 paramaeter di mana parameter pertama adalah variabel dari proses Image Data Generator pada data training, parameter kedua adalah jumlah batch yang akan dieksekusi pada setiap epochs, parameter ketiga adalah jumlah epochs yang akan dilakukan, parameter kedua adalah jumlah validasi pada setiap epochs dan parameter verbose berguna untuk menampilkan output dari proses training. Jumlah verbose yang digunakan adalah 2 yang artinya output yang ditampilkan hanya akan menyebutkan jumlah epochs tanpa menampilkan animasi proses. Lalu setelah fungsi fit, dilakukan evaluasi data loss dan accuracy dari proses training menggunakan fungsi evaluate. Hasil dari proses training dapat dilihat pada tabel 2 .

Tabel 2. Hasil Training Model

\begin{tabular}{|c|c|c|c|c|}
\hline $\begin{array}{c}\text { Jumlah } \\
\text { Epochs }\end{array}$ & Loss & Accuracy & Val Loss & $\begin{array}{c}\text { Val } \\
\text { Accuracy }\end{array}$ \\
\hline 1 & 0.7374 & 0.5667 & 0.7000 & 0.3500 \\
\hline 2 & 0.6768 & 0.5167 & 0.6559 & 0.8000 \\
\hline 3 & 0.6178 & 0.6552 & 0.5510 & 0.9500 \\
\hline 4 & 0.5328 & 0.7414 & 0.3678 & 1.0000 \\
\hline 5 & 0.4489 & 0.8833 & 0.3229 & 1.0000 \\
\hline 6 & 0.3998 & 0.9500 & 0.2659 & 0.9500 \\
\hline 7 & 0.1964 & 0.9828 & 0.1313 & 1.0000 \\
\hline 8 & 0.0887 & 1.0000 & 0.0117 & 1.0000 \\
\hline 9 & 0.0826 & 0.9500 & 0.0011 & 1.0000 \\
\hline 10 & 0.0260 & 0.9828 & $4.6433 \mathrm{e}-$ & 1.0000 \\
\hline $\begin{array}{c}\text { Test } \\
\text { Loss }\end{array}$ & \multicolumn{5}{|c|}{0.05663638934493065} \\
\hline $\begin{array}{c}\text { Test } \\
\text { accuracy }\end{array}$ & \multicolumn{5}{|c|}{} \\
\hline
\end{tabular}

Dapat dilihat pada tabel 2, rata-rata loss yang didapat adalah 0.056 jika dihitung dalam persentasi adalah $6 \%$ sedangkan jumlah 
accuracy yang didapatkan adalah 0.98 jika dalam persentasi adalah 98\%. Gambar 12 adalah visualisasi grafik proses training model.
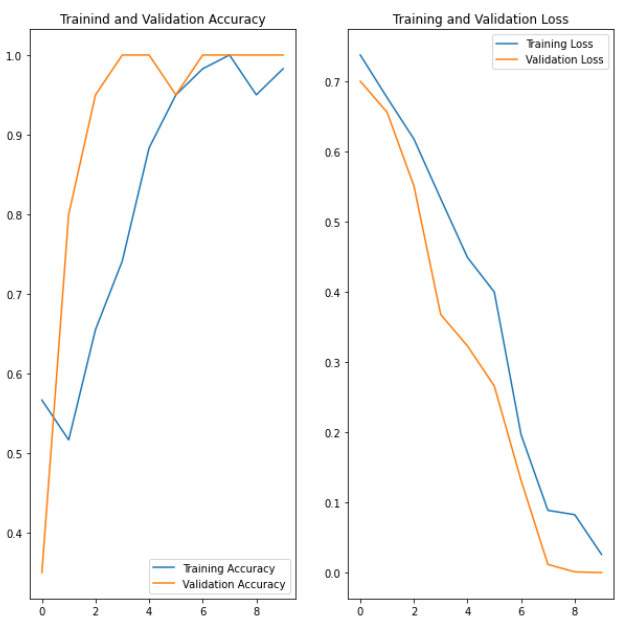

Gambar 12. Visualisasi Grafik Proses Training

Visualisasi grafik pada gambar 12 menunjukkan bahwa proses training pada akurasi mengalami kenaikan pada setiap epochs dan pada loss mengalami penurunan. Selanjutnya pada tahap terakhir adalah melakukan klasifikasi telur ayam fertil dan infertil. Proses klasifikasi dapat dilihat pada gambar 13 untuk telur ayam fertil dan 14 untuk telur ayam infertil.

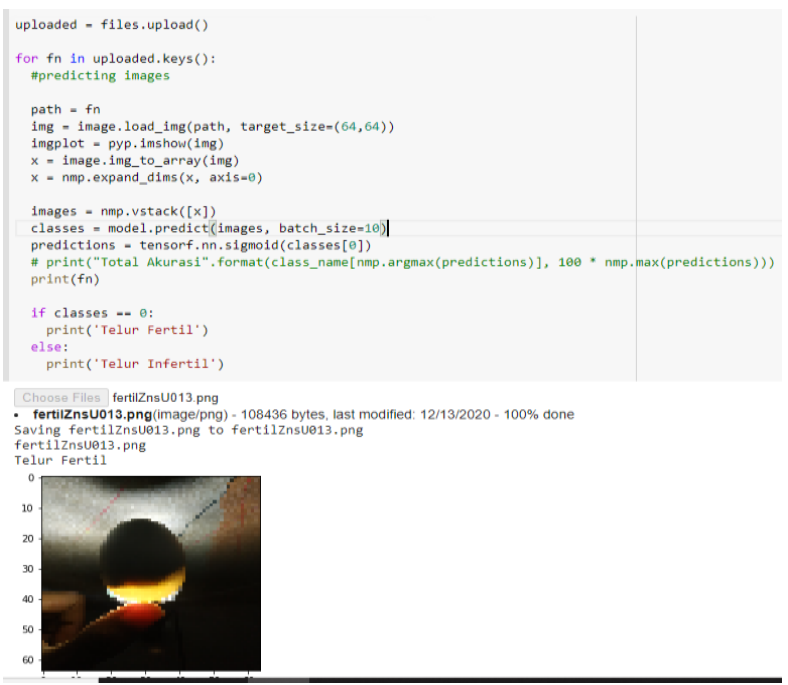

Gambar 13. Proses Klasifikasi Telur Ayam Fertil

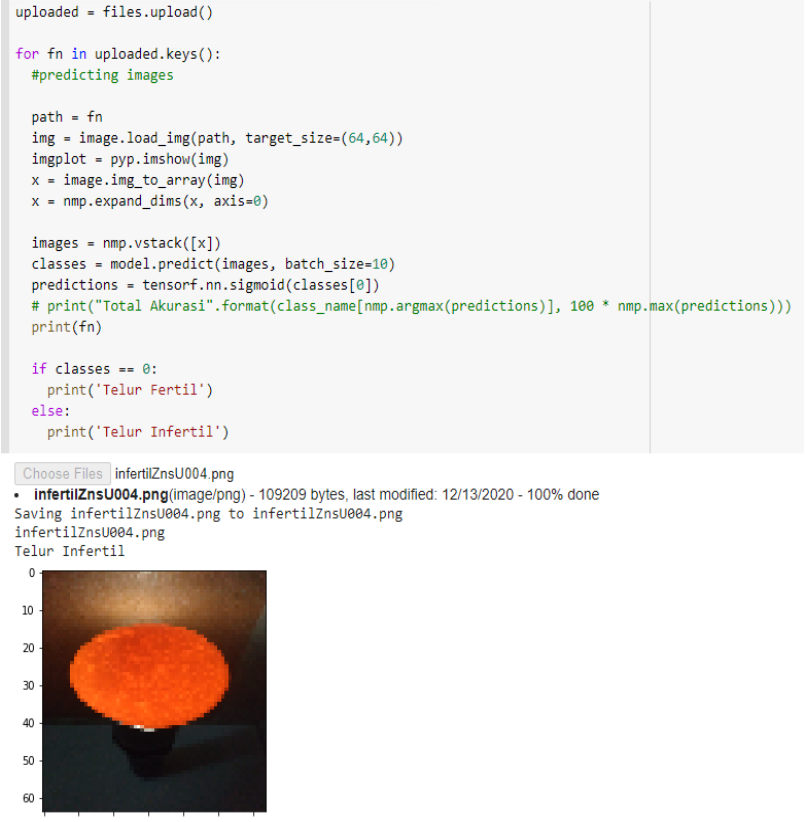

Gambar 14. Proses Klasifikasi Telur Ayam Infertil

Pada gambar 13 dan 14 dapat dilihat bahwa model yang telah dibuat mampu untuk mengklasifikasikan antara telur ayam fertil dan telur ayam infertile.

\section{Kesimpulan dan Saran}

Dari hasil penelitian ini dapat disimpulkan bahwa:

1. Penerapan Algoritma Convolutional Neural Network dapat diterapkan untuk mengklasifikasi telur ayam fertil dan telur ayam infertil

2. Nilai akurasi yang didapatkan pada proses klasifikasi adalah $98 \%$ dan nilai error sebesar 5\%

Sedangkan kekurangan dari penelitian ini adalah:

1. Data telur fertil yang diambil adalah telur yang sudah dierami selama 5 sampai 10 hari sehingga klasifikasi telur hanya dapat dilakukan pada hari-hari tersebut.

2. Dari grafik yang ada menunjukkan bahwa adanya kemungkinan jika proses training model mengalami overfitting karena nilai antara training dan validasi pada beberapa epochs terdapat perbedaan yang cukup signifikan. Hal tersebut disebabkan karena dataset yang didapatkan tidak cukup banyak untuk proses pelatihan dan validasi. 
Hasil penelitian ini masih dapat dikembangkan kembali dengan memperbanyak dataset agar proses training dapat terhindar dari overfitting.

\section{Referensi}

Arini, N. F., Ubaidillah, A., Wibisono, K. A., \& Ulum, M. (2020). Identifikasi embrio dalam telur berbasis image processing. Jurnal Teknik Elektro Dan Komputasi (ELKOM), 2(1), 11-19.

Diantoro, A., \& Santoso, I. B. (2017). Classification of Egg Fertility on the Image of Kampong Chicken Egg Using the Frequency Distribution Feature and Naive Bayes Classifier Algorithm's. Proceedings of the International Conference on Green Technology, 8(1), 446-453.

Felix, F., Wijaya, J., Sutra, S. P., Kosasih, P. W., \& Sirait, P. (2020). Implementasi Convolutional Neural Network Untuk Identifikasi Jenis Tanaman Melalui Daun. Jurnal SIFO Mikroskil, 2l(1), 1-10.

Ilahiyah, S., \& Nilogiri, A. (2018). Implementasi Deep Learning Pada Identifikasi Jenis Tumbuhan Berdasarkan Citra Daun Menggunakan Convolutional Neural Network. JUSTINDO (Jurnal Sistem Dan Teknologi Informasi Indonesia), 3(2), 49-56.

Isnawati, I. (2018). Klasifikasi Citra Candling Telur Ayam Kampung Dengan Metode LVQ.

Maimunah, M., \& Rokhman, T. (2018). Klasifikasi Penurunan Kualitas Telur Ayam Ras Berdasarkan Warna Kerabang Menggunakan Support Vector Machine. INFORMATICS FOR
EDUCATORS AND PROFESSIONAL: Journal of Informatics, 3(1), 43-52.

Nawawi, M. Z., Rahmad, R., \& Syahputra, M. (2015). Klasifikasi telur fertil dan infertil menggunakan jaringan saraf tiruan multilayer perceptron berdasarkan ekstraksi fitur warna dan bentuk. Jurnal Teknologi Informasi Dan Komunikasi, 4(2), 100-109.

Nurdiyah, D., \& Muwakhid, I. A. (2016). Perbandingan Support Vector Machine Dan K-Nearest Neighbor Untuk Klasifikasi Telur Fertil dan Infertil Berdasarkan Analisis Texture GLCM. Jurnal Transformatika, 13(2), 29-34.

Nurdiyah, D., Santosa, S., \& Pramunendar, R. A. (2015). Klasifikasi Citra Telur Fertil dan Infertil Dengan Analisis Tekstur Gray Level Co-Occurence Matrix dan Support Vector Machine. Cyberku Journal, 11(2), 116-126.

O'Shea, K., \& Nash, R. (2015). An introduction to convolutional neural networks. ArXiv Preprint ArXiv:1511.08458.

Prasmatio, R. M., Rahmat, B., \& Yuniar, I. (2020). Deteksi dan Pengenalan Ikan Menggunakan Algoritma Convolutional Neural Network. Jurnal Informatika Dan Sistem Informasi (JIFoSI), 1(2), 510-521.

Putra, I. (2016). Klasifikasi citra menggunakan convolutional neural network (CNN) pada caltech 101. Institut Teknologi Sepuluh Nopember.

Wulandari, I., Yasin, H., \& Widiharih, T. (2020). Klasifikasi CItra Digital Bumbu dan Rempah dengan Algoritma Convolutional Neural Network. Jurnal Gaussian, 9(3), 273-282. 